\title{
A Review of Body Mass Index Reduction Interventions Among Mexican Origin Latinos and Latinas
}

\author{
Fernando I. Rivera ${ }^{1}$, and Giovani Burgos ${ }^{2}$ \\ ${ }^{1}$ University of Central Florida, FL \\ ${ }^{2}$ McGill University, Quebec
}

\begin{abstract}
Objectives: A literature review was conducted to identify factors associated with successful Body Mass Index (BMI) reduction interventions for Mexican origin US Hispanic/Latino populations. Data Source: An academic database search was conducted of peer-reviewed literature primarily in public health, medical anthropology, medical sociology, and biomedical databases. The key search words used were "Latino or Hispanic or Mexican", in combination with "intervention", "obesity", "body mass index", "weight reduction", "best practices" and "lessons learned". Inclusion Criteria: The inclusion criteria included an intervention protocol, with BMI measures, and a majority of participants identified as Mexican origin Hispanics. Search results yielded a total of 118 articles with 19 studies meeting the inclusion criteria. Results: The review found that education and the use of culturally tailored/sensitive materials are important factors in BMI reduction. In addition, the study found that family centered and community based approaches are some of the most successful evidence based practices found in the Latino health literature. Conclusions: Obesity and its sequelae disproportionately impact both US and non-US Latino/ Hispanic communities and have life-long and intergenerational consequences. The findings from this review may serve as a guide to the development of more successful interventions and best practices to address the needs of Mexican origin Latino populations.
\end{abstract}

(C) 2012 Californian Journal of Health Promotion. All rights reserved.

Keywords: Hispanic/Latino, Mexican American, Body Mass Index, obesity, interventions, best practices

\section{Introduction}

A recent review of the literature on weight reduction intervention programs specifically targeting Hispanic groups found only three published studies from 1980 to 2006 (Lindberg \& Stevens, 2007). Indeed, Kumaniyka (2008) states that evidence with regard to obesity interventions among minority populations is "sparse, heterogeneous, and difficult to synthesize in any meaningful way" (p. 583). While the factors associated with obesity and being overweight are well known (Flegal, Ogden, \& Carroll 2004; Hedley, Ogden,
Johnson, Carroll, Curtin, \& Flegal, 2004; Ogden, Carroll, Curtin, McDowell, Tabak, \& Flegal, 2006; Ogden, Yanovski, Carroll, Flegal, 2007), there is scant information regarding the best practices of interventions and programs for Latinos targeting Body Mass Index (BMI) changes. This paper reviews the health literature to identify key evidence-based factors that have been found to be successful in reducing BMI levels in different weight loss and obesity interventions with Latino samples, primarily Mexican Americans. Specifically, the aims of the review are twofold: 1) identify interventions that aim to reduce BMI as one of their primary 
health outcomes, and 2) summarize how these interventions were able (or not) to achieve their desired BMI change. Ultimately, the review aims to provide a comprehensive review of the best practices that can inform policymakers and clinicians of effective ways to implement intervention programs targeting BMI reduction among Latinos/as of Mexican origin.

\section{Latinos and Obesity}

There is overwhelming evidence indicating that Latinos in the U.S. are at a high risk for obesity (Flegal, Ogden, \& Carroll, 2004; Lindberg \& Stevens, 2007) and related health consequences, such as diabetes (Narayan, Boyle, Thompson, Sorensen, \& Williams, 2003) and cardiovascular disease (Allison, Budoff, Wong, Blumenthal, Schreiner, \& Criqui, 2008). Alarmingly, this risk is found in Latino children and adolescents as well (Harrington, 2008).

Flegal, Carroll, Odgen, and Curtin (2010) reported that Mexican American adults have the highest obesity rates of all Hispanic groups (39.3\% vs. $37.9 \%$ respectively). Similarly, Mexican American children and adolescents are more likely to be obese than their non-Hispanic white counterparts (Ogden, Carroll Curtin, Lamb, \& Flegal, 2010).

The bulk of the Latino health literature has identified some factors putting Latinos (particularly Latino children) at risk for becoming obese and overweight. Some of these factors include higher levels of acculturation or adopting the lifestyles (e.g., eating processed foods) of the dominant group (Ahluwalia, Ford, Link, \& Bolen, 2007; Fuentes-Afflick \& Hessol, 2008), cultural health perceptions and practices (Ramirez, Chalela, Gallion, \& Velez, 2007; McGarvey, Collie, Fraser, Shuffllebarger, Lloyd, \& Oliver, 2006), poverty (Trevino, Fogt, Wyatt, Leal-Vazquez, Sosa, \& Woods, 2008), and sedentary behaviors (Sisson et al., 2009).

What is lacking in the literature is a synthesis of evidence-based interventions that have successfully addressed BMI reduction among Hispanics. Given the heterogeneity of Latino groups in the U.S., the current paper summarizes the results of weight loss and obesity interventions that measure BMI and targeted Latinos of Mexican origin. In the context of the review, interventions are not solely focused on those reducing BMI, but rather, the focus is on interventions in which BMI outcomes are measured and analyzed.

\section{Methods}

\section{Data Sources}

A computer search of peer-reviewed literature primarily in public health, medical anthropology (AnthroSource), medical sociology (Sociological Abstracts) and the National Library of Medicine database (PubMed) was used to gather the research articles included in the review. Key words used in the search were "Latino or Hispanic or Mexican" in combination with "interventions" ,"obesity", "body mass index", "weight reduction", "best practices" and "lessons learned". All of the search key words were entered individually by key word and outcome (e.g. "Latino and best practices").

\section{Inclusion and Exclusion Criteria}

After our literature search, studies were identified for inclusion using the following inclusion criteria: (1) interventions with pre and post test results; (2) a Latino or primarily Latino (50\% or more) study sample; (3) inclusion of each of the following outcome measures: BMI, body weight, weight loss, physical activity, and nutrition education; (4) studies conducted in the United States; (5) articles in English and published between 2000 and 2012. Search results yielded a total of 118 articles. After a careful review, the total number of articles that met the inclusion criteria equaled 31 articles. In order to meet the goals of the paper, two additional criteria items were included: sample of Mexican origin Latinos and BMI measures. These additional criteria stipulations reduced the number of articles reviewed to 19 .

\section{Categorization of Articles}

The articles that meet the inclusion criteria were divided into distinctive categories in relation to the focus of the intervention: cardiovascular disease, diabetes control/prevention, obesity/weight management, and physical activity. The articles that did not meet the 
inclusion criteria were organized in three categories: cultural/health beliefs, associated risk factors, and lessons learned/potential resources (A list of the articles is available from the authors upon request).

\section{Data Synthesis}

Tables 1 and 2 include the (1) authors and year of publication, (2) sample size, (3) study design and type of intervention, (4) BMI measures/assessments, and (5) results. In addition, all the articles are briefly summarized in the results section below. The tables and articles are divided according to whether or not the interventions achieved significant BMI reductions.

\section{Results}

\section{Interventions Achieving BMI reduction Diabetes Management}

Of the total 19 studies (see tables 1 and 2) that were reviewed for this study, four had a diabetes management component; of these four studies, three were successful in achieving significant BMI reductions (Babamoto, Sey, Camilleri, Karlan, Catalasan, \& Morisky, 2009; Vincent, 2009; Ojo, Beeson, Shultz, Firek, De Leon, Balcazar, \& Cordero-Macintyre, 2010). The successful diabetes management studies had three key characteristics in common. First, the interventions had a high degree of cultural sensitivity in that they took into account the patient's spiritual and cultural beliefs, tailored diets to include low fat variations of traditional foods, or incorporated health behavioral approaches (e.g., exercise) that were also culturally sensitive, such as walking and dancing. A second characteristic of successful programs was patient follow-ups that ranged from six weeks to three months. Individuals who were not monitored (i.e., those in control groups) and/or encouraged by intervention staff did not do as well as participants in the experimental groups. A third common characteristic of successful interventions was the use of Spanish to disseminate information about diabetes, diet, and exercise.
In the Amigos en Salud or Friends in Health intervention the authors utilized a randomized pre-post test measurement design to evaluate the effectiveness of a culturally-tailored outreach and education delivered by trained community health workers (CHW) to improve self-care behaviors and BMI reduction for newly diagnosed type 2 diabetic adult patients (Babamoto, Sey, Camilleri, Karlan, Catalasan, \& Morisky, 2009). The sample was $64 \%$ female. The training program consisted of a six-week curriculum including clinical policies and procedures, self-management strategies incorporating patient's spiritual and cultural beliefs, health behavior change theory, and other issues. Follow-up data indicated increases in self-rated health in the program delivered by community health workers and greater odds of reducing their BMI's, when compared to the other groups (case management and standard provider care). Furthermore, physical activity increased in all groups except in the case management group. The $\mathrm{CHW}$ program proved effective in reducing BMI and had the highest proportion of patients completing the study.

In another study, Vincent (2009) discussed the implementation and results of the Diabetes Education Program for Mexican Americans in Tucson, Arizona. This culturally-tailored intervention program for physical activity targeted 17 adult Mexican Americans (71\% were female), and utilized a two group randomized control design, with participants assigned to an intervention or control group. The intervention was an eight-week program that consisted of weekly two-hour group sessions. The curriculum included diabetes education, cooking demonstrations, and group support sessions. The program was culturally tailored to include low fat modifications of traditional foods, the utilization of home remedies, and culturally sensitive exercise practice such as dancing and walking. The program utilized a promotora (health promoter). The intervention group revealed a significant decrease in weight (nearly five pounds) and BMI (from 30.6 to 29.8). In addition, participants in the intervention group increased their physical 


\section{Table 1}

Mexican Origin Latinos/as Intervention Studies Achieving BMI Reduction

\begin{tabular}{|c|c|c|c|c|}
\hline Study & Sample Size & Study Design/Intervention & Measures/Assessments & Results \\
\hline $\begin{array}{l}\text { Diabetes Management } \\
\text { Babamoto et al. } 2009\end{array}$ & $\begin{array}{l}\text { Hispanic/Latino } \\
(\mathrm{n}=318) \\
\text { Mostly Mexican } \\
\text { descent }\end{array}$ & $\begin{array}{l}\text { Randomized controlled trial/ } \\
\text { community health worker }(\mathrm{CHW}) \text { lead } \\
\text { intervention }\end{array}$ & BMI, self-care behaviors & $\begin{array}{l}\text { Patients in CHW group had } 2.9 \text { times greater odds }(95 \% \text { confidence } \\
\text { interval) of decreasing their BMI }\end{array}$ \\
\hline Vincent 2009 & $\begin{array}{l}\text { Mexican Americans } \\
(\mathrm{n}=17)\end{array}$ & $\begin{array}{l}\text { Two group randomized control } \\
\text { design/Promotora lead intervention }\end{array}$ & $\begin{array}{l}\text { BMI, weight, physical } \\
\text { activity }\end{array}$ & $\begin{array}{l}\text { Intervention group had a significant decrease in BMI. Mean BMI } \\
\text { decrease from } 30.6 \text { at baseline to } 29.9 \text { at } 4 \text { weeks postintervention }\end{array}$ \\
\hline Ojo et al. 2010 & $\begin{array}{l}\text { Hispanic }(\mathrm{n}=39) \\
\text { Mostly Mexican } \\
\text { descent }\end{array}$ & $\begin{array}{l}\text { Non-random diabetes education } \\
\text { program }\end{array}$ & $\begin{array}{l}\text { BMI, glucose, insulin, } \\
\text { hemoglobin A1c, and serum } \\
\text { lipids }\end{array}$ & $\begin{array}{l}\text { Reduction in BMI }\left(-.15 \mathrm{~kg} / \mathrm{m}^{2}, \mathrm{p}=.40\right) \text { from baseline to three-month } \\
\text { values }\end{array}$ \\
\hline \multicolumn{5}{|l|}{$\begin{array}{l}\text { Obesity management/ } \\
\text { Weight loss }\end{array}$} \\
\hline Poston et al. 2003 & $\begin{array}{l}\text { Mexican American } \\
\text { women } \\
(\mathrm{n}=108)\end{array}$ & $\begin{array}{l}\text { Randomized, controlled, open-label } \\
\text { study/weight loss drug }\end{array}$ & BMI, weight & $\begin{array}{l}\text { Reduction in BMI }\left(\mathrm{kg} / \mathrm{m}^{2}\right) \text { in intervention group }(\mathrm{n}=56) \text { from } 6 \text { months } \\
(\mathrm{M}=34.8, \mathrm{SD}=5.5) \text { to } 12 \text { months }(\mathrm{M}=34.5, \mathrm{SD}=5.9) \mathrm{p}<0.001\end{array}$ \\
\hline Fullerton et al. 2007 & $\begin{array}{l}\text { Mexican American } \\
\text { children }(\mathrm{n}=80)\end{array}$ & $\begin{array}{l}\text { Random design /school-based weight } \\
\text { management program }\end{array}$ & $\begin{array}{l}\text { BMI z-score, weight, other } \\
\text { quality of life measures }\end{array}$ & $\begin{array}{l}\text { Reduction in BMIz-scores }(\mathrm{M}=-0.13, \mathrm{SD}=0.14) \mathrm{p}<0.05 \text { from baseline to } \\
6 \text { months }\end{array}$ \\
\hline Dreimane et al. 2007 & $\begin{array}{l}\text { Hispanic }(\mathrm{n}=192) \\
\text { Mostly Mexican } \\
\text { descent }\end{array}$ & $\begin{array}{l}\text { Hospital based, family centered } \\
\text { lifestyle program/exercise and nutrition } \\
\text { education }\end{array}$ & $\begin{array}{l}\text { Weight, BMI velocities } \\
\text { (change in value expressed in } \\
\text { units per time period) and } \\
\text { BMI z-scores }\end{array}$ & $\begin{array}{l}\text { BMI velocity decreased from } M=0.228, S D .=0.452 \text { to } M=-0.061 \text {, } \\
S D=0.548 \mathrm{~kg} / \mathrm{m}^{2} / \text { month }(p<.0001) \\
\text { BMI } z \text {-score rate (change in } z \text {-score per month) improved from } \\
M=0.011, S D=0.042 \text { to } M=-0.001, S D=.003 \text {-score } / \text { month }(p=0.006)\end{array}$ \\
\hline Johnston et al. 2007 & $\begin{array}{l}\text { Mexican American } \\
\text { children }(\mathrm{n}=60)\end{array}$ & $\begin{array}{l}\text { Random experimental design/physical } \\
\text { activity and nutrition education }\end{array}$ & zBMI, BMI, weight & $\begin{array}{l}\text { Children in the intervention group significantly reduced their BMI from } \\
\text { baseline to } 3 \text { months }(\mathrm{M}=-.056, \mathrm{SD}=0.69, \mathrm{p}<.05) \text { and from baseline to } 6 \\
\text { months }(\mathrm{M}=0.37, \mathrm{SD}=1.02, \mathrm{p}<.001) \\
\text { Children in the intervention group significantly reduced their zBMI from } \\
\text { baseline to } 1 \text { year }(\mathrm{M}=-.02, \mathrm{SD} .=0.2, \mathrm{p}<0.001) \text { and from baseline to } 2 \\
\text { years }(\mathrm{M}=-.02, \mathrm{SD}=-.0 .5, \mathrm{p}<.005)\end{array}$ \\
\hline \multicolumn{5}{|l|}{ Johnston et al. 2009} \\
\hline Fitzgibbon et al. 2012 & $\begin{array}{l}\mathrm{N}=146(94 \% \\
\text { Hispanic, } 86 \% \text { born } \\
\text { in Mexico })\end{array}$ & $\begin{array}{l}\text { Two group randomized control } \\
\text { design/School based obesity } \\
\text { intervention for } 3 \text { to } 5 \text { year old } \\
\text { Hispanic children and their parents }\end{array}$ & $\begin{array}{l}\text { BMI, BMI z-score, weight, } \\
\text { height, physical activity, diet }\end{array}$ & $\begin{array}{l}\text { Adjusted BMI }\left(\mathrm{kg} / \mathrm{m}^{2}\right) \text { change in intervention group after } 1 \text { year follow } \\
\text { up }(\mathrm{M}=-.043, \mathrm{SE} .=0.03, \mathrm{p}<.05)\end{array}$ \\
\hline Lindberg et al. 2012 & $\begin{array}{l}\text { Mexican American } \\
\text { women }(n=47)\end{array}$ & $\begin{array}{l}\text { Pretest-Posttest design/Culturally- } \\
\text { adapted intervention to reduce body } \\
\text { weight }\end{array}$ & BMI, weight, dietary intake & $\begin{array}{l}\text { BMI reduction from baseline }\left(38.7 \mathrm{~kg} / \mathrm{m}^{2}\right) \text { to } 6\left(34.7 \mathrm{~kg} / \mathrm{m}^{2}\right) \text { and } 12(33.2 \\
\left.\mathrm{kg} / \mathrm{m}^{2}\right) \text { month measures }(\mathrm{p}<0.0001) \text {. }\end{array}$ \\
\hline $\begin{array}{l}\text { Physical Activity } \\
\text { Keller \& Cantue } 2008\end{array}$ & $\begin{array}{l}\text { Mexican American } \\
\text { women }(\mathrm{n}=18)\end{array}$ & $\begin{array}{l}\text { Two group randomized design } \\
\text { /Promotora lead walking intervention. } \\
\text { Group I } 3 \text { days per week walking, } \\
\text { Group II } 5 \text { days per week walking. }\end{array}$ & BMI and body fat & $\begin{array}{l}\text { Significant difference in BMI over time. In Group I there were } \\
\text { differences between Time } 1(\mathrm{M}=36.53) \text { and Time } 2(\mathrm{M}=34.44 . \mathrm{p}<.003) \text {, } \\
\text { Time } 1 \text { and Time } 3(\mathrm{M}=30.39, \mathrm{p}<.001) \text {, and Time } 1 \text { and Time } 3(\mathrm{p}<.005) \\
\text { measures. For Group II there were only significant differences between } \\
\text { Time } 1(\mathrm{M}=32.44) \text { and Time } 2(\mathrm{M}=33.53, \mathrm{p}<.003)\end{array}$ \\
\hline
\end{tabular}

$\mathrm{M}=\mathrm{Mean} \mathrm{SD}=$ Standard Deviation $\mathrm{SE}=$ Standard Error 


\section{Table 2}

\section{Mexican Origin Latinos/as Intervention Studies not Achieving BMI Reduction}

\begin{tabular}{|c|c|c|c|c|}
\hline Study & Sample Size & Study Design/Intervention & Measures/Assessments & Results \\
\hline $\begin{array}{l}\text { Cardiovascular } \\
\text { Keller \& Trevino } 2001\end{array}$ & $\begin{array}{l}\text { Mexican American women } \\
(\mathrm{n}=36)\end{array}$ & Randomized clinical trial/walking & BMI, weight & $\begin{array}{l}5 \text { walking days per week group } \mathrm{BMI} \\
\text { at Time } 1(\mathrm{M}=33.17, \mathrm{SD}=8.31) \text { and } \\
\text { at Time } 3(\mathrm{M}=33.87, \mathrm{SD}=8.77) \text {. No } \\
\text { significant BMI change }\end{array}$ \\
\hline
\end{tabular}

Martyn-Nemeth et al. 2010

$\mathrm{N}=16(94 \%$ born in Mexico $)$

Pretest/posttest culturally designed exercise program

\section{Obesity management/ \\ Weight loss}

Coleman et al. 2005

Hispanic children $(\mathrm{n}=833)$

Mostly Mexican descent

Cullen et al. 2009

Physical Activity

Staten et al. 2004

Spruijt-Metz et al. 2008

Low income women Mexican descent $(n=151)$

Mexican heritage Latina girls $(\mathrm{n}=335)$
$\mathrm{N}=1,104$ (97\% women, $89 \%$ Hispanic) Mexican descent

$\mathrm{N}=1289$ (94\% Hispanic) Mostly

Mexican descent

$\mathrm{N}=217$ (Hispanic 74\%)

Mostly Mexican descent
Untreated, matched control group

design/translation of national

program

Two group randomized trial/ food and nutrition program

Randomized experimental

design/school initiated cognitive and

behavioral program

Randomized experimental design/ community health worker lead intervention

Randomized experimental design/ exercise program

Experimental design/ classroom

animation intervention
BMI, hemoglobin Alc, lipid panel, and psychological well-being

BMI, weight, and other health measures

BMI, dietary behaviors

BMI, BMI z-score, weight, height

Physical activity, fruit and vegetabl intake, BMI

Physical activity, BMI

Physical activity, BMI
No BMI reduction between pre-test $(\mathrm{M}=33, \mathrm{SD}=6)$ and post-test (M33,

$\mathrm{SD}=6$ ) measures

All children had increases in BMI from year to year.

Significant BMI decrease at post $(\mathrm{M}=30.9, \mathrm{SD}=0.3)$ compared to baseline measures $(\mathrm{M}=31.4, \mathrm{SD}=0.3$, $\mathrm{p}<.05$ ). Not maintained at follow up $(\mathrm{M}=31.1, \mathrm{SD}=0.3, \mathrm{p}<.05)$

No significant differences in BMI

outcome between the control an

intervention schools $(\mathrm{p}=0.22)$

No significant BMI reduction on the three intervention groups (Provider counseling group; Provider counseling and health education group; Provider counseling, health education and community health worker group)

BMI and body composition failed to change, despite increased physical activity and improved fitness No significant BMI percentile * change for intervention group at baseline $(\mathrm{M}=66.44, \mathrm{SD}=2.90)$ and follow up $(\mathrm{M}=66.85, \mathrm{SD}=2.80)$

$\mathrm{M}=$ Mean, $\mathrm{SD}=$ Standard Deviation *BMI percentile was calculated according to the age and gender specific Center for Disease Control and Prevention (CDC) growth curves for pediatric populations. 
activity (walking) levels. Finally, Ojo, Beeson, Shultz, Firek, De Leon, Balcazar, \& CorderoMacintyre (2010) examined the results of a diabetes education pilot program for Hispanic adults (13 males, and 18 females). Program participants attended diabetes education classes weekly for three months, with monthly follow up sessions. There were several outcome measures (e.g. glucose, insulin, dietary intake, etc) along with BMI. The results indicated a reduction in BMI from baseline to three-month measures. Overall, this culturally sensitive diabetes education program was successful in improving the dietary intake and serum lipid profiles of study participants and a reduction in BMI.

Obesity Management/Weight Loss Interventions There were six studies in this category, which constitute the bulk of the work documenting reduction in BMI. One common characteristic in these studies that was associated with weight reduction among participants was the active engagement and follow-up of participants by intervention staff. The monitoring of exercise and diet through food diaries, and education about nutrition proved to be particularly effective in leading to weight reduction. Other effective study characteristics were the inclusion of family members and/or friends in training sessions, the use of contracts and incentives to motivate and encourage participants, reinforcement of nutritional and physical goals, and intensive and individualized instruction. One study even used a family-based-hip-hop intervention as a way of being culturally sensitive.

For instance, some participants assumed that adding vinegar and lime juice to fried foods made the food less caloric (Lindberg, Stevens, Vega-López, Kauffman, Rosales Calderón, \& Cervantes, 2012). One challenge that intervention staff encounter was dispelling nutritional myths while being culturally sensitive, which was achieved by incorporating traditional foods into the dietary goals of the program, and involving family members on how to make healthy food choices, and controlling portion size. Another technique that was effective was the use of behavioral strategies that involved individualized incentives to increase health behaviors, such as including family members in the training sessions, and educating parents and family members about healthy eating habits. As expected, the incorporation, monitoring, and encouragement of exercise was a crucial and effective component of weight reduction interventions, particularly instructions on how to exercise that included family members. The use of Spanish was, surprisingly, not necessary for weight reduction in these studies.

Poston and colleagues (2003) utilized a culturally sensitive weight loss intervention combined with Orlistat (a weight loss drug that prevents the absorption of fat) among a sample of overweight and obese adult Mexican American women $(n=108)$. Participants were randomly assigned to the experimental or control group. The experimental group received Orlistat, behavior modification strategies, nutrition activities including food diaries, a nutrition manual, and physical activity objectives (Five times per week for $30 \mathrm{~min}$ ). Contracts and incentives were used to motivate participants, and participants were encouraged to adhere to the medication regimen by returning all medication containers. Individuals in the experimental group who completed the study and a final evaluation experienced significant weight loss and BMI reduction in comparison to the control group. There was an eight percent weight loss, $7.9 \mathrm{~kg}$ (17.4 pounds) at six months and $8.6 \mathrm{~kg}$ (18.9 pounds) at 12 months. Another study evaluated Quality of Life (QOL) measures (including age/gender specific BMI z-scores) with a group sixth and seventh grade Mexican American children $(n=80)$ participating in a six month school-based weight management program (Fullerton, Tyler, Johnston, Vincent, Harris, \& Foreyt, 2007). Participants were randomly assigned into an instructor-lead intervention (ILI) or self help (SH) intervention. Those in the ILI group attended one nutrition class and four physical activities classes per week for 12 weeks. In addition, they were given behavioral strategies to increase healthy behaviors, with monthly parent training sessions. Meanwhile, the SH group was given instructions to follow in a self-help manual without any 
instructor assistance. All materials were in English. Results indicated reduction in weight status for those in the ILI group. Furthermore, the ILI group experienced enhanced quality of life that was associated with a reduction in BMI percentiles.

Similarly, Dreimane, Safani, MacKenzie, Halvorson, Braun, Conrad, and Kaufman (2007) analyzed the effectiveness of the Kids N Fitness program. The Kids N Fitness was a hospital based, family centered lifestyle program designed to decrease weight in overweight (BMI> 85th percentile) children (7-17 years). Over a period of six years, 417 children enrolled in the program, and 153 dropped out, for a final sample of 264 participants (137 female, 127 males, and $73 \%$ Hispanic). During the first two years the program lasted eight weeks, later the program was extended to 12 weeks. Pre and post tests analyses were used to compare the effectiveness of the program. Weekly sessions consisted of exercise (45 minutes), nutrition education/behavior modification, and family involvement (45 minutes). In addition, participants were asked to keep a daily dietary and exercise journal. There were no significant differences in weight change by age, gender or ethnicity. Results indicated a significant reduction in weight velocity. In addition, those who attended more sessions showed better outcomes in decreases in weight, BMI velocities, (change in value expressed in units per time period) and BMI percentile scores. In another study, Johnston, Tyler, McFarlin, Poston, Haddock, Reeves, \& Foreyt (2007) reported the results of a randomized controlled trial that was completed by sixty overweight students ( 33 boys and 27 girls between the ages of 10 and 14 years). Those who participated in the self-help group (control) were provided a weight management book and the program was led by parents in 12 weekly sessions. Participants in the intensive instruction group (experimental) received nutrition instruction (one day a week), and participated in 35 to 40 minutes of physical activity (four days a week) during the 12 week-intervention. A token economy system was implemented to reinforce nutritional and physical goals, through which points were awarded for meeting program and individual goals in exchange for weekly prizes. The program was also individualized to meet the needs and preferences of participants. Compared to the control group, children in the intensive instruction group had significant changes in their BMI percentiles at three and six month intervals. The six month interval was taken after the conclusion of the program. In 2009, the authors conducted a two year follow up and found that participants in the intensive instruction group showed significant decreases in BMI percentiles at one and two years compared to the control group (Johnston, Tyler, McFarlin, Poston, Haddock, Reeves, \& Foreyt, 2010).

In 2012, Fitzgibbon and colleagues reported the results of the Family-Based-Hip-Hop to Health school-based obesity intervention. Designed for 3-5 year old Latino children ( $\mathrm{n}=146,73 \%$ female) and their parents, the program was administered in four Head Start preschools in the Chicago Public Schools system. Schools were randomly assigned to a Family-Based Intervention (FBI) or a General Health Intervention (GHI). The 14 week program included child and parent interventions. The FBI child group met three times a week and included nutrition instruction and aerobic activity. The GHI group met once a week and received information on general health concepts. The FBI parent component included classes and newsletters, and were encouraged to attend six weekly classes on healthful eating/family exercise and perform moderate physical activity. Parents in the GHI received weekly newsletters that paralleled the 14 week school-based component. BMI and BMI percentiles were lower at the one year follow up in both children groups. There was no significant BMI parent changes at post-intervention or one year follow up. Still, the authors attributed the decrease in BMI percentiles to the recognition of obesity as a growing public health problem.

The last study reviewed was De Por Vida (Give for Life) program (Lindberg, Stevens, VegaLópez, Kauffman, Rosales Calderón, \& Cervantes, 2012). This 12 month weight-loss intervention pilot study program targeted 47 obese Spanish speaking Mexican-American women. The intervention was culturally adapted 
and based on behavioral strategies from other English speaking weight loss programs. The cultural adaptations included: women-only participants and interventionists, minimal written materials, and a focus on Mexican traditions, among others. Forty seven women enrolled in the program and twenty six completed the 12 month follow up. There was a BMI reduction from baseline to six and 12 month measures. The open filtering criteria for enrollment, attendance requirements and incentives created an "open-door" policy that the authors attributed to the success of the program.

The interventions that were not very effective tended to be less culturally sensitive. Keller and Trevino (2001) targeted BMI reduction in a group of premenopausal over weight (BMI > 25) Mexican women by assigning them to one of two groups, a low frequency experimental group that was advised walk three days a week for 30 minutes, a high frequency group that was told to walk five days a week for 30 minutes. While the low frequency group experienced reductions of serum cholesterol and body fat, the high frequency group experienced weight gain. While participants were encouraged to record and log their walking activity, the interventions were not culturally tailored. Although Martyn-Nemeth, Vitale, and Cowger (2010) incorporated cultural elements in their BMI intervention, such as social/emotional support from family members, dietary recommendations using familiar foods, and weekly educational session that lasted over three months, the results showed no significant changes in BMI over the course of the study. The authors conclude that the lack of success in the reduction of BMI was probably due to the focus on exercise rather than on weight loss. A similar finding of increased physical activity but no significant changes in BMI was reported by Hovell et al. (2008). These scholars also attributed the lack of success on BMI reductions to a focus on exercise rather than diet. This insight is consistent with the strategies of successful studies that focus on diet modification and weight loss, in addition to exercise.

\section{Interventions not Achieving BMI Reduction Cardiovascular Interventions}

Of the 19 studies reviewed (see Table 2), only one had a cardiovascular focus and it did not achieve any significant BMI reduction. In detail, Keller and Trevino (2001) conducted a 24 week randomized clinical trial to evaluate the effects of walking on cardiovascular disease risk factors, primarily overweight (BMI>25) and sedentary behaviors. The study tested the effects of two walking frequencies (high and low) in a group of 18 premenopausal overweight (BMI>25) Mexican American women. The low frequency experimental group was advised to walk three days a week for 30 minutes. The high frequency group was told to walk for five days a week for 30 minutes. Both groups received weekly telephone calls from the interventionists for encouragement and support for the walking program. The control group gained around six pounds and increased their BMI by two increments; meanwhile, the low-frequency group lost three pounds and one BMI increment. The high frequency group gained an average of three pounds and had a slightly increase in their BMI, assumed to be due to poor adherence and high dropout rates. The intervention was successful in bringing changes from sedentary to active behavior, but failed to achieve clinically meaningful body mass changes. The authors suggested that this was due to the short duration of the trial and the poor adherence of the women in the study.

\section{Diabetes Interventions}

One of the four diabetes interventions reviewed (see Table 2) was not successful in reducing BMI. Martyn-Nemeth, Vitale, and Cowger (2010) examined the effectiveness of an exercise program intervention for Hispanics (primarily of Mexican origin) with type two diabetes $(n=16$, 14 females and two males). The program utilized a nonrandomized pretest/protest design to assess the effects of the exercise program on selected outcomes, including BMI. The results revealed no overall changes in BMI from baseline to post-exercise session measures. The authors suggest that the lack of change in BMI among participants might be due to the focus of the program (physical activity rather than weight loss), gained muscle mass contributing to increased body weight, and perhaps, that 
participants gained fitness independent from weight loss.

\section{Physical Activity Interventions}

Three interventions were successful in increasing physical activity among participants, but they did not result in weight reduction. In the Arizona Well-Integrated Screening and Evaluation for Women Across the Nation (WISEWOMAN) Project (Staten, GregoryMercado, Ranger-Moore, Will, Guiliano, Ford, \& Marshall, 2004), participants $(n=217)$ in the 12-month program were assigned to one of three intervention groups. The low intensity group consisted of counseling from a provider; the second group received health classes and a newsletter, in addition to counseling; the high intensity group received the same as the other groups, in addition with social support provided by a community health worker. There were no significant decreases in weight or BMI for all groups; nonetheless, all groups increased the number of minutes of modest to vigorous physical activity at the end of the intervention. Hovell et al. (2008) tested the effects of a culturally tailored exercise intervention. One hundred fifty-one sedentary low income Latinas were randomly assigned to an experimental $(n=75)$ or control group $(n=76)$. Those in the intervention group participated in three weekly, 90 minute group exercise sessions for six months. Participants were also given diet/exercise education sessions that included culturally appropriate activities. The sessions were in Spanish and appropriate for low-literacy Latinas. Study results indicated increases in vigorous activity, walking and cardio-respiratory fitness. There were no significant changes in BMI or body composition. The authors emphasized the positive fitness increases in light of the tremendous cultural, social, and environmental barriers to routine physical activity.

Lastly, Spruijt-Metz, Nguyen-Michel, Goran, Chou, and Huang (2008) analyzed the results of a school-based intervention designed to increase physical activity and decrease sedentary behavior in a sample of 459 middle school female students with a mean age of 12.5 years. Seven schools participated in the study (four experimental and three control schools). The intervention group was asked to develop a media-based physical activity animated Public Service Announcement in collaboration with a studio company. Students were given information about physical activity and sedentary behaviors. Health outcomes were measured three months before and after the intervention. Results from the intervention showed no significant effects on BMI or body fat. The results indicated success in decreasing sedentary behaviors, but not as effective in increasing physical activity.

Obesity Management/Weight Loss Interventions Three interventions reviewed had a weight loss focus (Table 2). The first study analyzed the results of the El Paso Child and Adolescent Trial for Cardiovascular Health $(\mathrm{CATCH})$ program (Coleman, Tiller, Sanchez, Heath, Sy, Milliken, \& Dzewaltowski, 2005). In El Paso, Texas 896 third grade students (423 girls and 473 boys) participated in the program and were followed through the fourth and fifth grades. The study utilized a pre-test and post-test, matched control group, and quasi-experimental design to measure different health outcomes. Most participants were Hispanic, with a large percent eligible for public assistance and limited English proficiency. Schools in the intervention group received financial support to implement the program (for more information about the CATCH program, see Heath \& Coleman 2002/2003). Overall, the program successfully slowed the risk of becoming overweight among study participants, but there was no effect on BMI. All children had increases in BMI from year to year. The second study with a weight loss focus was the Building Healthy Families: Step by Step (BHF) intervention (Cullen, Smalling, Thompson, Watson, Reed, \& Konzelmann, 2009); the BHF is a modified curriculum of the Texas Expanded Food and Nutrition Education Program (EFNEP). The EFNEP ( $n=1,104,97 \%$ female) is a food and nutrition education program for limited resource families. The BHF included an intervention video, a discussion guide, and additional supporting materials. Assessments were taken at baseline (session one), post (session eight), and at a four mouth follow up. There was a 
significant decrease in BMI in the BHF group from baseline to post assessment, in comparison to the EFNEP group, but the change was not maintained at follow up. In addition, improvements in dietary behaviors were observed in all study participants.

Finally, Klish, Karavias, White, Balch, Kennard Fraley, Mikahil, Abrams, Terrazas, Smith, and Wong (2012) analyzed the results of a cognitive and behavioral experimental program that took place in a primarily Hispanic, low income area of Houston. A control school $(n=510,49.4 \%$ female) with similar demographics and in the same area was matched to the intervention school ( $n=779,46.3 \%$ female). The one schoolyear intervention program consisted of lectures, behavior modification sessions, and other nutrition education activities. Study results showed no significant differences in BMI outcome between the control and intervention schools. The authors suggest that the program might have been more effective if it was initiated by parents, rather than schools.

\section{Discussion}

The studies reviewed utilized a variety of strategies to reduce BMI among Latinos of Mexican Origin. They include community health worker initiated interventions (Babamoto et al., 2009), the use of promotoras (Keller \& Cantue, 2008; Vincent, 2009), experimental drugs (Poston et al., 2003), the use of culturally sensitive materials and activities (Lindberg et al., 2012; Ojo et al., 2010), middle school interventions (Fullerton et al. 2007; Johnston et al., 2007/2009) 2012), pre-school interventions (Fitzgibbon et al., 2012), and family-centered interventions (Dreimane et al., 2007). It is encouraging that these interventions have been effective in reducing BMI. Nonetheless, while these seem to be successful at the individual level, most of the studies reviewed were in lowincome communities at a high risk for obesity and being overweight. Attention to environmental conditions (such as poverty, unsafe neighborhoods, unemployment, family demands, etc.) must be taken into account in promoting these seemingly successful BMI reduction interventions.
Some of the best practices found in the review of the literature included: family centered interventions where all family members were involved in promoting healthy lifestyles; bilingual and culturally tailored/sensitive materials; the use of community health workers and promotoras; use of meal plans; the importance of promoting and implementing interventions in school settings (particularly in pre-school and middle schools); and establishing community-based programs in existing institutions, such as schools. Most diabetes interventions were successful in reducing BMI. Perhaps the diagnosis of diabetes serves as a "wakeup call" for the necessity for change by individuals to improve their health behaviors and nutrition patterns.

These findings lend support to other articles that have looked at obesity-related interventions in the general (non-Latino) population. Such general population studies have identified a number of factors that appear to be important in BMI interventions, such as interventions targeting diet and exercise in various institutional contexts, including the community, school, and family levels (see Foltz, May, Belay, Nihiser, Dooyema, \& Blanck, 2012; Story, Kaphingst, Robinson-O’Brien, \& Glanz, 2008). Other factors that seem to be related to promising interventions in the general population are intensive counseling and followups (McTigue, Hess, \& Ziouras, 2006), the inclusion of family members in promoting healthy lifestyles (Niemeier, Hektner, \& Enger, 2012), the involvement of parent in school based-interventions (Van Lippevelde, Verloigne, De Bourdeaudhuij, Brug, Bjelland, Lien, \& Maes, 2012), including the larger social network of participants in the intervention (Economos, Hyatt, Goldberg, Must, Naumova, Collins, \& Nelson, 2007), and the pairing of education about healthy eating habits with psychical activity (see Haynos \& O'Donohue, 2012; Kropski, Keckley, \& Jensen, 2008).

Still, the dominant consensus is that there is no "magic bullet" in terms of the most important factor leading to weight reduction and lower BMI; also, the evidence is inconclusive in terms of what is the best research design to capture the 
effects of successful factors (see Haynos \& O’Donohue, 2012).

The interventions not achieving BMI reduction included those promoting physical activity (Hovell et al., 2008; Keller \& Trevino, 2001; Martyn-Nemeth, Vitale, \& Cowger, 2010, Staten et al., 2004), those implemented at elementary schools (Coleman et al., 2005; Klish et al., 2012), and those where parents and family members were not involved in the intervention process (Klish et al., 2012). It is noteworthy to point out that most interventions encouraging physical activity were not successful in reducing BMI. One possible explanation is that increased physical activity results in gained muscle mass and thus to an increase in body weight (MartynNemeth, Vitale, \& Cowger, 2010). Alternatively, there might be a limited understanding of the benefits of exercise (Hovell et al., 2008). Another interesting finding was the lack of success in reducing BMI in elementary school settings. A plausible explanation is that in both interventions (Coleman et al., 2005; Klish et al., 2012), physical activity was encouraged and the results are similar to other interventions promoting physical activity (gained in muscles mass). Alternatively, a family centered approach, where children and parents are equally involved, might be essential in successfully reducing BMI in this population.

Overall, these practices suggest that BMI reduction is a community effort; as such, attention must be given to the particular community's cultural, social, and economic realities. For instance, a number of scholars pointed out that attention needs to be paid to personal and institutional barriers that make interventions less effective, including personal barriers (age, sedentary habits, and physical disability) and environmental barriers like the lack of affordable/accessible exercise facilities, neighborhood crime, and the need for child care. While some practices have been found to be effective, it can be concluded that there is no single factor or magic practice that is bound to encompass the difficult process of BMI reduction in the Latino community. Nonetheless, it is encouraging that several interventions are targeting the Latino community (particularly children) and that there seems to be a continuous effort to understand and study the factors associated with effective BMI reduction interventions.

\section{Conclusion}

This paper reviewed published articles that addressed some of the best practices and factors behind successful BMI reduction interventions targeting Mexican origin Latino groups. The review found that education and the use of culturally tailored/sensitive materials are important factors in BMI reduction. In addition, the study found that family centered and community based approaches are some of the best evidence-based practices found in the Latino health literature. Taken as a whole, the emergence of studies found in the literature is encouraging since the publication of Linderberg and Stevens 2007 article, which found only three weight reduction intervention programs specifically targeting Latino groups. Nonetheless, a simple keyword search for "obesity interventions" in The National Center for Biotechnology Information PubMed database yielded 6,428 results, while the search for "obesity interventions and Latinos" yielded only 177 results (searched 7/9/12). The studies reviewed found several interventions targeting children. It is imperative to target young Latino children as they are increasingly at risk for suffering from obesity related chronic conditions, a few of them including diabetes, cardiovascular diseases.

\section{Limitations}

Most of the limitations of studies discussed in previous reviews of weight loss interventions (Lindberg \& Stevens 2007; Kumanyika 2008) were also found in studies included in this review. These limitations include a lack of control groups, a lack of information about how Hispanic status was determined, and no data collected on acculturation levels, language spoken at home, and time living in the U.S. Furthermore, there are few details on how interventions were culturally implemented and adapted (outside of the provision of materials in Spanish). Finally, as noted before, the bulk of the evidence is on low income Mexican American women and children. Hence, the 
findings of this study may not fully represent the findings of Mexican American men.

This study is significant as it documents the best practices and factors associated with successful BMI reduction interventions with Latinos/as of Mexican Origin. Because obesity continues to be a pandemic with life-long and intergenerational impact within Latino communities, the findings from this paper can be used as a resource for researchers, health scholars, and policymakers, enabling them to emulate and expand on the best practices to reduce BMI.

\section{Acknowledgements}

This study was funded by the Latino Overweight \& Obesity Education Awareness \& Prevention Initiative with support from the U.S. Department of Health and Human Services Office of Minority Health $(\mathrm{OMH})$ and the Inter-University Program for Latino Research (IUPLR) at the University of Notre Dame. We would like to thank Kathleen M. Fallon and anonymous reviewers for helpful feedback on this manuscript.

\section{References}

Ahluwalia, I. B., Ford, E.S., Link, M., \& Bolen. J.C. (2007). Acculturation, weight, and weight-related behaviors among Mexican Americans in the United States. Ethnicity \& Disease Journal, 17, 643 649.

Allison, M. A., Budoff, M.J., Wong, N.D., Blumenthal, R. S., Schreiner, P. J., \& Criqui, M.H. (2008). Prevalence of and risk factors for subclinical cardiovascular disease in selected US Hispanic ethnic groups: the Multi-Ethnic Study of Atherosclerosis. American Journal of Epidemiology, 167, 962-969.

Babamoto, K. S., Sey, K. A., Camilleri, A. J., Karlan, V. J., Catalasan, J., \& Morisky, D.E. (2009). Improving diabetes care and health measures among Hispanics using community health workers: results from a randomized controlled trial. Health Education \& Behavior, 36, 113-126.

Burgos, G. (2012). Latino Youth. In G. Ritzer (Ed.), Blackwell Encyclopedia of Sociology. Malden, MA: Blackwell Publishers.

Coleman, K. J., Tiller, C. L., Sanchez, J., Heath, E.M., Sy, O., Milliken, G., \& Dzewaltowski, D.A. (2005). Prevention of the epidemic increase in child risk of overweight in low-income schools: the El Paso coordinated approach to child health. Archives of Pediatrics \& Adolescent Medicine, 159, 217-224.

Cullen, K. W., Lara Smalling, A., Thompson, D., Watson, K.B., Reed, D., \& Konzelmann, K. (2009). Creating healthful home food environments: results of a study with participants in the expanded food and nutrition education program. Journal of Nutrition Education \& Behavior, 41, 380-388.

Dreimane, D., Safani, D., MacKenzie, M., Halvorson, M., Braun, S., Conrad, B., \& Kaufman, F. (2007). Feasibility of a hospital-based, family-centered intervention to reduce weight gain in overweight children and adolescents. Diabetes Research \& Clinical Practice, 75, 159-168.

Economos, C. D., Hyatt, R. R., Goldberg, J. P., Must, A., Naumova, E. N., Collins, J. J. et al. (2007). A community intervention reduces BMI z-score in children: Shape up Somerville first year results. Obesity, 15(5), 1325-1336.

Fitzgibbon, M.L., Stolley, M.R., Schiffer, L., Kong, A., Braunschweigh,C.L., Gomez-Perez, S.L., Odoms-Young, A., Van Horn, L., Kaufer Christoffel, K., \& Dyer, A.R. (2012). Family-based Hip-Hop to Health: Outcome Results. Obesity, Accepted article preview online: May 29, 2012.

Flegal, K.M., Carroll, M.D., Ogden, C.L., \& Curtin, L.R. (2010). Prevalence and Trends in Obesity Among US Adults, 1999-2008. Journal of the American Medical Association, 303, 235-241.

Flegal, K. M., Ogden, C.L., \& Carroll, M.D. (2004). Prevalence and trends in overweight in MexicanAmerican adults and children. Nutrition Reviews, 62, S144-148.

Foltz, J. L., May, A. L., Belay, B., Nihiser, A. J., Dooyema, C. A., \& Blanck, H. M. (2012). Populationlevel intervention strategies and examples for obesity prevention in children. Annual Review of Nutrition, 32, 391-415. 
Fuentes-Afflick, E., \& Hessol, N. A. (2008). Acculturation and body mass among Latina women. Journal of Women's Health, 17, 67-73.

Fullerton, G., Tyler, C., Johnston, C.A., Vincent, J.P., Harris, G.E., \& Foreyt, J.P. (2007). Quality of life in Mexican-American children following a weight management program. Obesity, 15, 2553-2556.

Harrington, S. (2008). Overweight in Latino/Hispanic adolescents: scope of the problem and nursing implications. Pediatric Nursing, 34, 389-394.

Haynos, A. F., \& O’Donohue, W. T. (2012). Universal childhood and adolescent obesity prevention programs: review and critical analysis. Clinical Psychology Review, 32(5), 383-399.

Heath, E. M., \& Coleman, K.J. (2002). Evaluation of the institutionalization of the coordinated approach to child health $(\mathrm{CATCH})$ in a U.S./Mexico border community. Health Education \& Behavior, 29, 444-460.

Heath, E.M., \& Coleman, K.J. (2003). Adoption and institutionalization of the Child and Adolescent Trial for Cardiovascular Health $(\mathrm{CATCH})$ in El Paso, Texas. Health Promotion Practice, 4, $157-$ 164.

Hedley, A. A., Ogden, C. L., Johnson, C.L., Carroll, M.D., Curtin, L.R., \& Flegal, K.M. (2004). Prevalence of overweight and obesity among US children, adolescents, and adults, 1999-2002. Journal of the American Medical Association, 291, 2847-2850.

Hovell, M. F., Mulvihill, M.M., Buono, M.J., Liles, S., Schade, D.H., Washington, T.A., Manzano, R., \& Sallis, J.F. (2008). Culturally tailored aerobic exercise intervention for low-income Latinas. American Journal of Health Promotion, 22, 155-163.

Johnston, C. A., Tyler, C., McFarlin, B.K., Poston, W.S., Haddock, C.K., Reeves, R., \& Foreyt, J.P. (2007). Weight loss in overweight Mexican American children: a randomized, controlled trial. Pediatrics, 120, e1450-1457.

Johnston, C. A., Tyler, C., McFarlin, B.K., Poston, W.S., Haddock, C.K., Reeves, R., \& Foreyt, J.P. (2010). Effects of a school-based weight maintenance program for Mexican-American children: Results at 2 years. Obesity, 18, 542-547.

Keller, C. S., \& Cantue, A. (2008). Camina por Salud: walking in Mexican-American women. Applied Nursing Research, 21, 110-113.

Keller, C., \& Trevino, R.P. (2001). Effects of two frequencies of walking on cardiovascular risk factor reduction in Mexican American women. Research in Nursing \& Health, 24, 390-401.

Klish, W., Karavias, K.E., White, K.S., Balch, A.J., Kennard Fraley, J., Mikahil, C., Abrams,S.H., Terrazas, N.L., O’Brian Smith, E. \& Wong, W.W. (2012). Multicomponent school-initiated obesity intervention in a high-risk, Hispanic elementary school. Journal of Pediatric Gastroenterology and Nutrition, 54, 113-116.

Kropski, J. A., Keckley, P. H., \& Jensen, G. L. (2008). School-based obesity prevention programs: an evidence-based review. Obesity 16(5), 1009-1018

Kumanyika, S. (2008). Ethnic minorities and weight control research priorities: where are we now and where do we need to be? Preventive Medicine, 47, 583-586.

Lindberg, N. M., \& Stevens, V.J. (2007). Review: weight-loss interventions with Hispanic populations. Ethnicity \& Disease Journal, 17, 397-402.

Lindberg, N.M., Stevens, V.J., Vega-López, S., Kauffman, T.L., Rosales Calderón, M., \& Cervantes, M.A. (2012). A weight-loss intervention program designed for Mexican-American women: Cultural adaptations and results. Journal of Immigrant and Minority Health. Published online: March 30, 2012. Doi: 10.1007/s10903-012-9616-4

Martyn-Nemeth, P.A., Vitale, G.A., \& Cowger, D.R. (2010). A culturally focused exercise program in Hispanic adults with type 2 diabetes: a pilot study. The Diabetes Educator, 36, 258-267.

McGarvey, E. L., Collie, K.R., Fraser, G., Shufflebarger, C., Lloyd, B., \& Oliver, M.N. (2006). Using focus group results to inform preschool childhood obesity prevention programming. Ethnicity \& Health, 11, 265-285. 
McTigue, K. M., Hess, R., \& Ziouras, J. (2006). Obesity in Older Adults: A Systematic Review of the Evidence for Diagnosis. Obesity, 14(9), 1485-1497.

Narayan, K. M., Boyle, J.P., Thompson, T.J., Sorensen, S.W., \& Williamson, D.F. (2003). Lifetime risk for diabetes mellitus in the United States. Journal of the American Medical Association, 290, 1884-1890.

Niemeier, B. S., Hektner, J. M., \& Enger, K. B. (2012). Parent participation in weight-related health interventions for children and adolescents: a systematic review and meta-analysis. Preventive Medicine, 55(1), 3-13.

Ogden, C.L., Carroll, M.D., Curtin, L.R., Lamb, M.M., \& Flegal., K.M. (2010). Prevalence of high body mass index in U.S. children and adolescents, 2007-2008. Journal of the American Medical Association, 303, 242-249.

Ogden, C. L., Carroll, M.D., Curtin, L.R., McDowell, M.A., Tabak, C.J., \& Flegal, K.M. (2006). Prevalence of overweight and obesity in the United States, 1999-2004. Journal of the American Medical Association, 295, 1549-1555.

Ogden, C. L., Yanovski, S.Z, Carroll, M.D., \& Flegal, K.M. (2007). The epidemiology of obesity. Gastroenterology, 132, 2087-2102.

Ojo, E., Beeson, L., Shultz, E., Firek, A., De Leon, M., Balcazar, H., \& Cordero-Macintyre, Z. (2010). Effect on the EnBalance, a culturally and language-sensitive diabetes education program, on dietary changes and plasma lipid profile in Hispanic diabetics. International Journal of Body Composition and Research, 8 (Supp), S69-76.

Poston, W. S., Reeves, R.S., Haddock,C.K., Stormer, S., Balasubramanyam, A., Satterwhite, O., Taylor, J.E., \& Foreyt, J.P. (2003). Weight loss in obese Mexican Americans treated for 1-year with orlistat and lifestyle modification. International Journal of Obesity \& Related Metabolic Disorders, 27, 1486-1493.

Ramirez, A. G., Chalela, P., Gallion, K., \& Velez, L.F. (2007). Energy balance feasibility study for Latinas in Texas: a qualitative assessment. Preventing Chronic Disease, 4, A98.

Sisson, S. B., Church, T.S., Martin, C.K., Tudor-Locke, C., Smith, S.R., Bouchard, C., Earnest, C.P., Rankinen, T., Newton, R.L., \& Katzmarzyk, P.T. (2009). Profiles of sedentary behavior in children and adolescents: the US National Health and Nutrition Examination Survey, 2001-2006. International Journal of Pediatric Obesity, 4, 353-359.

Spruijt-Metz, D., Nguyen-Michel, S.T., Goran, M.I., Chou, C.P., \& Huang, T.T. (2008). Reducing sedentary behavior in minority girls via a theory-based, tailored classroom media intervention. International Journal of Pediatric Obesity, 3, 240-248.

Staten, L. K., Gregory-Mercado, K. Y., Ranger-Moore, J, Will, J.C., Giuliano, A.R., Ford, E.S., \& Marshall, J. (2004). Provider counseling, health education, and community health workers: the Arizona WISEWOMAN project. Journal of Women's Health, 13, 547-556.

Story, M., Kaphingst, K. M., Robinson-O'Brien, R., \& Glanz, K. (2008). Creating healthy food and eating environments: policy and environmental approaches. Annual Review of Public Health, 29, 253-272.

Trevino, R. P., Fogt, D.L., Wyatt, T.J., Leal-Vasquez, L., Sosa, E., \& Woods, C. (2008). Diabetes risk, low fitness, and energy insufficiency levels among children from poor families. Journal of the American Dietetic Association, 108, 1846-1853.

Van Lippevelde, W., Verloigne, M., De Bourdeaudhuij, I., Brug, J., Bjelland, M., Lien, N. et al. (2012). Does parental involvement make a difference in school-based nutrition and physical activity interventions? A systematic review of randomized controlled trials. International Journal of Public Health, 57(4), 673-678.

Vincent, D. 2009. Culturally tailored education to promote lifestyle change in Mexican Americans with type 2 diabetes. Journal of the American Academy of Nurse Practitioners, 21, 520-527. 
Rivera, F. I., Burgos, G. / Californian Journal of Health Promotion 2012, Volume 10, Special Issue: Health Disparities in Latino Communities, 99-113

\author{
Author Information \\ *Fernando I. Rivera, $\mathrm{PhD}$ \\ University of Central Florida \\ Department of Sociology \\ Email: Fernando.Rivera@ucf.edu
}

Giovani Burgos

McGill University

* corresponding author 